\title{
Lithography Techniques for Optical Nanometric Materials and Nanowires
}

\author{
Digambar Jakkan \\ Electronics and Telecommunication Department, Trinity Academy of Engineering, Pune India \\ d.jakkan@gmail.com
}

\begin{tabular}{|l|l|}
\hline Article History & \multicolumn{1}{|c|}{ Abstract } \\
$\begin{array}{l}\text { Article Submission } \\
04 \text { October 2021 } \\
\text { Revised Submission } \\
16 \text { November 2021 } \\
\text { Article Accepted }\end{array} 10 \begin{array}{l}\text { Lithography is a basic advance to be taken in the creation procedure of coordinated } \\
\text { circuits. There is an imperative job of nano and optical gadgets in the present and } \\
\text { future applications. Subsequently, this work canter's around cutting edge and } \\
\text { improved lithography systems on those coordinated circuits. In NFO deposition, } \\
\text { Article Published } 2021\end{array}$ \\
$\begin{array}{l}\text { photograph separation can occur through non full conditions because of the } \\
\text { inalienable properties of the optical nanometric field. Nano photolithography } \\
\text { utilizing an Optical-Field Non resounding to electronic changeover method makes it } \\
\text { conceivable to utilize different sources to store an assortment of nano metric } \\
\text { materials. This impossible to miss photochemical response of an optical close to field } \\
\text { can be applied to photochemical reaction. Nano manipulation is a significant } \\
\text { innovation to create and amass nanostructures, particularly for the uneven } \\
\text { structures. In the strategy, the organized plane of substrate was created by laser- } \\
\text { intrusion lithography. Nano-wires were controlled on the organized surfaces through } \\
\text { nano-opto grippers in material field. The technique utilizes an example to take care } \\
\text { of the issue that a solitary nanowire is too little to even think about being gotten and } \\
\text { controlled with nano grippers. } \\
\text { Keywords: Photolithography; Nano manipulation; laser intrusion lithography; } \\
\text { Chemical vapor deposition }\end{array}$ \\
\hline
\end{tabular}

\section{Introduction}

The Optical close fields are given to standard microscopy, high-thickness optical memory, molecule control, etc. The spatial area comparatively prompts novel physical marvels, for example, optically no-no vitality move and brute second consonant age. These marvels happen considering the way that optical close to fields don't agree to a section of the corporeal standards of the far fields. Common optical CVD, as showed up in Fig 1, uses a twoadvance procedure: photo separation and absorption. For photo segment, light should reverberate the responding sub-atomic gasses to enable particles from the soonest beginning stage to a fortified state. The past researches decide holds this reverberation is key for excitation. The engaged particles by then relax up to the segment channel, and the separated Zn particles adsorb to the substrate surface. Regardless, photo parcel can occur under non-stunning conditions, considering the brand name properties of optical close to fields. Beginning late, the photo parcel of metal ordinary particles and the affirmation of $\mathrm{Zn}$ contacts utilizing a non-resounding optical close to field is winning with a photonic centrality with criticalness hole condition of the atom. This photochemical response starts from the raised spatial inclination of the optical close to field. In spite of CVD, these wires can be implemented in photo-chemical technologies.

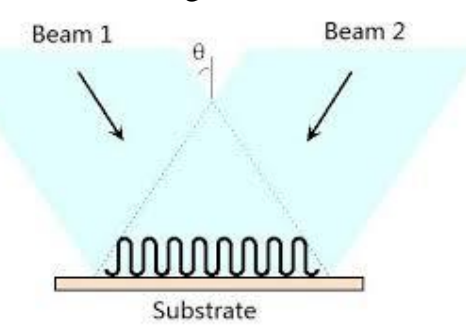

Figure 1. Nanomanipulation of single nanowires on structured surfaces 
(a)

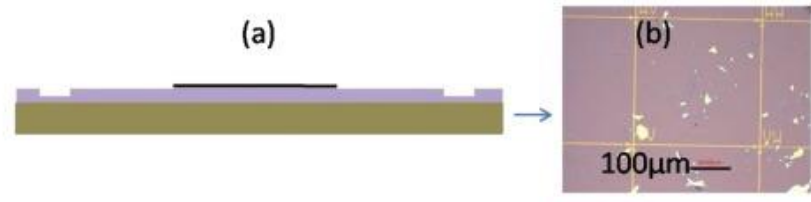

(c)

(d)

(e)

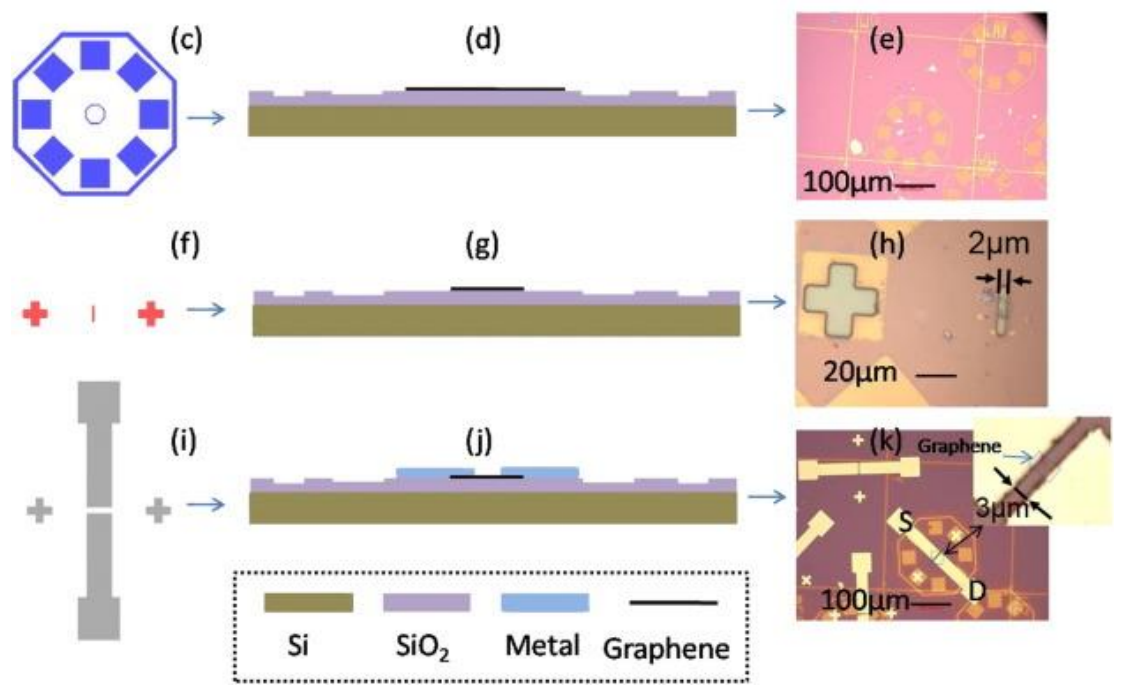

Figure 2: Optical lithography technique for the fabrication of nano devices

Nano control is optimized by organizing and control of accuracy estimation and gathering on nano-wires. It takes a gander at various wonders in the nano-world, and makes nano-materials, gadgets and structures by coordinating the nuclear, atomic, and different things. This improvement is relied on to be unavoidable in its applications across for all intents and purposes all advances. There are right now various techniques that have been made to perform nano-control undertakings subject to various devices, for example, filtering test enhancing point of convergence, optical cables \& nano-grippers. Here, a framework for control of single nanowires, as showed up in Fig 2, on sifted through surfaces by nano-grippers is introduced. This framework take control of single nano-wires underneath 100pm in broadness.

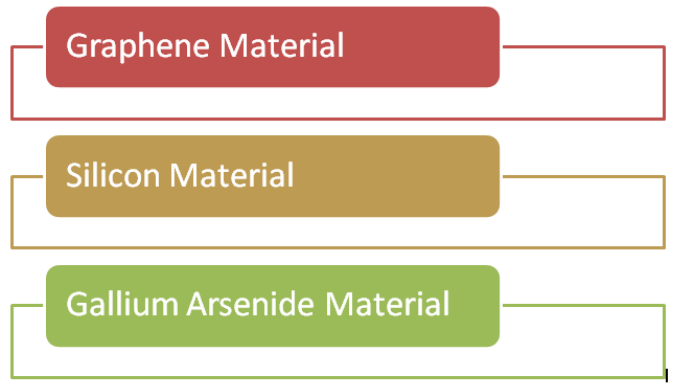

\section{References}

Figure 3: Material selection for Optical lithography technique

[1] T. Kawame, K. Kobayashi. J. Lim, Y. Narita, and M. Ohtsu, "Direct observation of optically forbidden energy transfer between $\mathrm{CuCl}$ quantum cubes via near-field optical spectroscopy," Phys. Rev. Lett. vol. 88, no. 6, pp. 067404-14, 2002.

[2] T. Kawazoe, Y. Yamamoto. and M. Ohtsu, "Fabrication of a nanometric Zn dot by non-resonant near field optical chemical vapor deposition,” Appl. Phys. Lett., vol. 79, pp. 1184-1186, 2001.

[3] Z. Wang, D. Li, J. Zhang, Z.Ji and R. Qiu, "Robotic Nano assembly: Current Developments and Challenges," International Journal of Computer Applications in Technology, vol. 41, pp. 185-194, 2011. 